\title{
Patient-reported outcomes and considerations in the management of COPD: focus on indacaterol/ glycopyrronium bromide
}

This article was published in the following Dove Medical Press journal: Patient Preference and Adherence

\author{
Erminia Ridolo' \\ Irene Pellicelli' \\ Bruna Gritti² \\ Cristoforo Incorvaia ${ }^{2}$ \\ 'Allergy and Clinical Immunology, \\ Medicine and Surgery Department, \\ University of Parma, Parma, Italy; \\ ${ }^{2}$ Cardiac/Pulmonary Rehabilitation \\ Unit, ASST Pini-CTO, Milan, Italy
}

Correspondence: Erminia Ridolo University of Parma, Via Gramsci n. I4, Parma 43।26, Italy

Tel +3952I 702028

Fax +39521703920

Email erminia.ridolo@unipr.it Department of Medicine and Surgery,

\begin{abstract}
Dual bronchodilation with long-acting beta-2 agonists and muscarinic antagonists is recommended in patients with severe to very severe COPD. Among dual bronchodilator combinations, indacaterol/glycopyrronium combination (IGC) received evidence of higher efficacy and good safety compared with monotherapy with either drug as well as with tiotropium. In randomized controlled trials, the primary outcome is usually the change in mean $\mathrm{FEV}_{1}$ resulting from treatment. However, the functional aspects that influence the physician's choice of the type of management may not be considered important by the patient, based on his perception of the disease. To address such issue, patient-reported outcomes (PROs) were assessed in recent studies. They include patient's perception of breathlessness, physical functioning, global health status, quality of life, use of rescue medications, and patient's report of COPD exacerbations. PRO data from the studies showed a clear improvement in patients' awareness of a better control of the disease in patients treated with IGC. In addition, the latest literature on two important issues influencing patient's preference and adherence, ie, the once-daily administration and the device to be used, confirmed the effectiveness of IGC and the ability of its device $\left(\right.$ Breezhaler $\left.^{\mathbb{B}}\right)$ to result in patient's satisfaction, ease of use, less handling errors, and self-assurance to have inhaled the entire dose.
\end{abstract}

Keywords: severe COPD, dual bronchodilation, long-acting beta-2 agonists, long-acting muscarinic antagonists, efficacy, patient's perception

\section{Introduction}

Indacaterol and glycopyrronium belong to the latest generation of beta- 2 agonists and muscarinic antagonists, respectively, to be used as bronchodilators in patients with COPD. A large number of trials have demonstrated, as summarized in review articles, the efficacy and safety of indacaterol, ${ }^{1-4}$ glycopyrronium, ${ }^{5-8}$ and the combination of the two drugs. ${ }^{9-12}$ This scientific evidence was highlighted by meta-analyses, resulting in comparable efficacy and safety of both bronchodilators. The first meta-analysis on indacaterol was performed in 2013, including six randomized controlled trials (RCTs) of at least 12 weeks; the parameter used was the OR for likelihood of active treatment at different doses to reduce dyspnea compared with placebo. The ORs were 1.784 (95\% CI 1.282-2.482) for the dose of $75 \mu \mathrm{g}, 2.149$ (95\% CI 1.746-2.645) for the dose of $150 \mu \mathrm{g}$, and 2.458 (95\% CI 2.010-3.006) for the dose of $300 \mu \mathrm{g} .{ }^{13}$ Later in the same year another meta-analysis included 12 RCTs with a global population of 10,997 patients, with the primary outcome of $\mathrm{FEV}_{1}$ changes at 12 weeks of treatment. Other bronchodilators, including formoterol, salmeterol, and tiotropium were used as comparators. FEV improved in indacaterol-treated patients compared to placebo 
patients by a weighted mean difference (MD) of $0.16 \mathrm{~L}$ (95\% CI 0.15-0.18 L, $P<0.001$ ). Efficacy of indacaterol was similar to formoterol, salmeterol, and tiotropium. $\cdot{ }^{14}$ In 2015 a Cochrane meta-analysis of 13 RCTs with 9,961 participants was performed, ten trials involving an indacaterol vs placebo comparison, five trials involving an indacaterol vs twice-daily salmeterol, formoterol, and eformoterol comparison. The trial duration was between 12 and 52 weeks. By the Cochrane criteria, an overall strong quality of evidence was found, and the risk of significant bias was minimal in most RCTs. The primary objectives were to compare trough $\mathrm{FEV}_{1}$ at the end of dosing, exacerbation rates, and quality of life (QoL). Compared with placebo, a significant and clinically relevant improvement in trough $\mathrm{FEV}_{1}$ was detected with indacaterol, based on a MD of $149.11 \mathrm{~mL}$ (95\% CI 137.09-161.12). Compared with placebo, a significant improvement in QoL, as measured by the St George Respiratory Questionaire (SGRQ) was found. Compared with twice-daily beta-2 agonists, a small but significant increase in trough $\mathrm{FEV}_{1}$ was observed with indacaterol (MD $61.71 \mathrm{~mL}, 95 \%$ CI 41.24-82.17). Data were insufficient to analyze the differences in exacerbation. The authors concluded that in patients with stable COPD, indacaterol treatment results in significant and clinically meaningful improvements in lung function and QoL compared to placebo. ${ }^{15}$

Despite several RCTs evaluated the efficacy of glycopyrronium compared with placebo or other bronchodilators, no meta-analysis exclusively addressing glycopyrronium is available thus far. In a systematic review and network meta-analysis comparing the efficacy of long-acting muscarinic antagonist monotherapies including aclidinium, glycopyrronium, umeclidinium, and tiotropium, which used as primary end point the 12 -week trough $\mathrm{FEV}_{1}$, the efficacy of glycopyrronium was comparable to tiotropium, which is the established class standard. ${ }^{16}$ A meta-analysis on effectiveness and safety of the indacaterol/glycopyrronium combination (IGC) compared with other first-line drugs, particularly tiotropium, is available. Based on the changes in functional indicators and QoL, the authors concluded that IGC was more effective and as safe as tiotropium. ${ }^{17}$ The whole evidence on efficacy and safety in COPD patients of indacaterol, glycopyronium, and their combination is a key factor in driving the physician's treatment choice. According to the guidelines on obstructive lung disease (GOLD), either indacaterol or glycopyronium may be prescribed in mild to moderate disease (GOLD level 1-2), while their combination may be prescribed in severe or very severe disease (GOLD level 3-4), inhaled corticosteroids (ICS) being also indicated in the latter. ${ }^{18}$ However, the factors influencing physician's decision are not necessarily working in patient's feeling of disease. This makes essential to appreciate the factors influencing the COPD patient preference concerning inhaled bronchodilators.

\section{The role of patient-reported outcomes}

As mentioned earlier, the primary end points of RCTs on COPD treatment usually consist of objective measures such as respiratory functional indexes, especially $\mathrm{FEV}_{1}$ and dyspnea scales. However, to define more precisely the burden of disease as well as the efficacy of a treatment, assessment tools based on patient-reported outcomes (PROs) are needed, the most frequently used being breathlessness, physical functioning, and global health status; the association between PRO data and improved lung function as measured by $\mathrm{FEV}_{1}$ in 2016 was deemed to be variable, and weak for long-acting $\beta$-2 agonist (LABA)/long-acting muscarinic antagonist (LAMA) combinations. ${ }^{19}$ However, a recent pooled analysis including $23 \mathrm{RCTs}$ resulted in a different appraisal. In fact, using as PROs dyspnea, as measured by transition dyspnea index (TDI), QoL, as measured by SGRQ, frequency of COPD exacerbations, and use of rescue medication, significant correlations were observed between trough $\mathrm{FEV}_{1}$ and PROs concerning better SGRQ and TDI scores, less exacerbations, and less rescue medication use. In all end points, active treatments were significantly superior to placebo; in particular, LABA/LAMA treatment achieved better outcomes than either single component. ${ }^{20}$

Focusing on IGC, PRO data from five RCTs, one post hoc analysis, one pooled analysis, and one real-life study are available. Table 1 summarizes the main figures from these studies. The first two RCTs were performed in 2013. In the SPARK study, IGC was compared, based on blinded randomization, with glycopirronium alone or with openlabel tiotropium. The PRO used as primary objective was the rate of moderate-to-severe COPD exacerbations, as defined by worsening respiratory symptoms. The results showed the superiority of the dual bronchodilator in respect of glycopyrronium alone in preventing moderate-to-severe exacerbations, as well as in improving health status and lung function. ${ }^{21}$ The BEACON study compared in patients with stage II or stage III COPD the efficacy of IGC vs the concurrent administration of indacaterol plus glycopyrronium (IND + GLY) for 4 weeks. Actually, the primary end point was to assess the noninferiority of IGC compared with IND + GLY by the changes in trough $\mathrm{FEV}_{1}$, but symptom scores 
Table I Patient-reported outcomes from studies comparing indacaterol/glycopyrronium combination compared with other treatments

\begin{tabular}{|l|l|l|l|l|}
\hline $\begin{array}{l}\text { Authors } \\
\text { (reference) }\end{array}$ & $\begin{array}{l}\text { Kind of } \\
\text { study }\end{array}$ & $\begin{array}{l}\text { No of } \\
\text { patients }\end{array}$ & PROs used & Results \\
\hline Wedzicha et al ${ }^{21}$ & RCT & 2,224 & Rate of COPD exacerbations & $\begin{array}{l}\text { Significant reduction of exacerbation rate with } \\
\text { IGC vs glycopyrronium alone }\end{array}$ \\
\hline Dahl et al ${ }^{22}$ & RCT & 193 & Symptom score and rescue medication use & $\begin{array}{l}\text { Similar reductions in symptom score and rescue } \\
\text { medications with IGC vs concurrent use of } \\
\text { indacaterol and glycopyrronium }\end{array}$ \\
\hline Mahler et al ${ }^{23}$ & RCT & 247 & $\begin{array}{l}\text { Patient's reported dyspnea and rescue } \\
\text { medication use }\end{array}$ & $\begin{array}{l}\text { Significant reduction of dyspnea and rescue } \\
\text { medications vs placebo and tiotropium }\end{array}$ \\
\hline Wedzicha et al24 & RCT & 1,680 & Annual rate of COPD exacerbations & $\begin{array}{l}\text { Significant reduction of exacerbation rate with } \\
\text { IGC vs salmeterol/fluticasone }\end{array}$ \\
\hline $\begin{array}{l}\text { Kardos and } \\
\text { Hagedorn-Peinz }\end{array}$ & RCT & 88 & Patient's preference and satisfaction & $\begin{array}{l}\text { Significantly higher preference and adherence } \\
\text { with IGC vs tiotropium }\end{array}$ \\
\hline Tsiligianni et al ${ }^{26}$ & $\begin{array}{l}\text { Pooled } \\
\text { analysis }\end{array}$ & 6,108 & $\begin{array}{l}\text { Health status, dyspnea, symptoms, and rescue } \\
\text { medication use }\end{array}$ & $\begin{array}{l}\text { Significant improvement in all comparators with } \\
\text { IGC vs placebo, salmeterol/fluticasone, and } \\
\text { indacaterol or glycopyrronium in monotherapy }\end{array}$ \\
\hline Anzueto et al ${ }^{27}$ & $\begin{array}{l}\text { Post hoc } \\
\text { analysis }\end{array}$ & 3,362 & $\begin{array}{l}\text { Rate of COPD exacerbations, time to first } \\
\text { moderate-to-severe exacerbation, and change } \\
\text { from baseline in quality of life (SGRQ) }\end{array}$ & $\begin{array}{l}\text { Significant reduction in rate of exacerbation } \\
\text { and time to first exacerbation with IGC vs } \\
\text { salmeterol/fluticasone Comparable quality of life }\end{array}$ \\
\hline Plusa et al28 & $\begin{array}{l}\text { Observational } \\
\text { study }\end{array}$ & 633 & $\begin{array}{l}\text { Health status and level of dyspnea } \\
\text { The best results were achieved with IGC vs } \\
\text { indacaterol or glycopyrronium in monotherapy }\end{array}$ \\
\hline
\end{tabular}

Abbreviations: RCT, randomized controlled trial; PRO, patient-reported outcome; IGC, indacaterol/glycopyrronium combination; SGRQ, St George Respiratory Questionaire.

and rescue medication use were also used as PROs. In both treatment groups, a comparable reduction in symptom scores and rescue medication use was found. ${ }^{22}$ The following RCT, named BLAZE study, was aimed at comparing the effects of IGC on dyspnea, as measured by a self-administered computerized version of the TDI, vs placebo and tiotropium after 6 weeks of treatment. Further end points were rescue medication use and lung function. A significant difference in TDI total score in favor of IGC compared with placebo $(P<0.001)$ and tiotropium $(P=0.021)$ was detected. Also, a significant improvement in lung function and a significantly lower use of rescue medication were found with IGC compared to the other treatments. ${ }^{23}$ In the FLAME study, the effects of co-administration of indacaterol and glycopyrronium were compared with those from the combination of the LABA salmeterol plus the ICS fluticasone $(50 / 500 \mu \mathrm{g})$ twice daily during 52 weeks in COPD patients with exacerbations in previous years, using as primary objective the rate of COPD exacerbation. At the final analysis, the rate of exacerbations was $11 \%$ lower in the indacaterol-glycopyrronium group than in the salmeterol-fluticasone group $(P=0.003)$, and the time to the first exacerbation was longer for the indacaterolglycopyrronium group than the salmeterol-fluticasone group ( 71 days vs 51 days, $P<0.001$ ); also, the time to the first severe exacerbation was longer for the indacaterolglycopyrronium group $(P=0.046)$. These data drove the authors to conclude that indacaterol-glycopyrronium was more effective than salmeterol-fluticasone in preventing COPD exacerbations. ${ }^{24}$ In the FAVOR study were compared the effects of IGC vs tiotropium on peak $\mathrm{FEV}_{1}$ and also on PROs including patient satisfaction and treatment preference. COPD patients treated with tiotropium prior to enrollment were recruited and randomized to receive once daily either open-label IGC for 4 weeks followed by 4 weeks of tiotropium or vice versa. The primary end point was $\mathrm{FEV}_{1}$ changes after the treatment period. Patients completing the study had significantly higher $\mathrm{FEV}_{1}$ after 4 weeks of treatment with IGC vs tiotropium $(P=0.0017)$, and IGC was preferred over tiotropium among both patients and physicians. More patients were very satisfied or satisfied with IGC (79\%) compared with tiotropium (58\%) concerning dyspnea reduction. The authors highlighted the importance of the improvement of a pivotal PRO such as of patient's dyspnea perception with the open-label IGC compared with tiotropium. ${ }^{25}$

A pooled analysis of data from patients with COPD who had participated to six RCTs compared the effects of IGC vs other treatments including salmeterol/fluticasone, glycopyrronium, tiotropium, and placebo. Lung function was measured and health status, dyspnea, other symptoms, and rescue medication use were employed as PROs. Despite significant differences in baseline parameters between men and women, IGC treatment resulted in significantly improved 
lung function vs placebo and all active comparators in men and women. Also, the improvement in dyspnea and health status and the reduction of rescue medication use was higher with IGC compared with all other treatments in both sexes, though the results were generally better in women than in men. ${ }^{26}$

A post hoc analysis of the FLAME study evaluated whether IGC reduced the risk of clinically important deterioration compared with salmeterol/fluticasone 50/500 $\mu \mathrm{g}$ twice daily in moderate-to-very severe COPD patients. The judgment of deterioration included a $\geq 100 \mathrm{~mL}$ decrease in $\mathrm{FEV}_{1}$ or $\geq 4$-unit increase in SGRQ total score or a moderateto-severe COPD exacerbation, as assessed by changes from baseline to the end of study after 52 weeks. IGC treatment reduced the incidences of deteriorations and significantly delayed the time to clinically important deterioration $(P<0.0001)$ compared with salmeterol/fluticasone. After 12 weeks, from starting until study ending, patients with clinically important deteriorations had a significantly higher rate of moderate-to-severe exacerbations compared with patients without clinically important deterioration. No significant difference was detected concerning the SGRQ total score in the two treatment groups. ${ }^{27}$

Finally, a real-life study in Poland evaluated the impact of routinely administered treatment with either indacaterol, glycopyrronium, or both on PROs from COPD patients, which consisted of health status as assessed by the clinical COPD questionnaire and the level of dyspnea as measured by the modified Medical Research Council (mMRC). The observation period was 26 weeks from the start of treatment. Only procedures of standard, current practice were applied. Improvement in clinical COPD questionnaire and mMRC scores was observed in all treatment groups, but the best results were achieved with the combination of indacaterol and glycopyrronium. ${ }^{28}$ Actually, in a recent review on the available PROs in obstructive respiratory diseases, the clinical COPD questionnaire and the COPD assessment test were recommended, based on validity/reliability, responsiveness, practicality, and the short time necessary for completion, for use in both primary care and other clinical settings of daily practice. ${ }^{29}$

\section{Further issues to assess through patient-reported outcomes}

A key issue in patient's preference is the number of daily drug administrations. Therefore, the once-daily use of indacaterol and glycopyrronium in respect to the twice-daily use of other beta- 2 agonists and muscarinic antagonists is potentially important. In a cohort study on a large population of 5,869 patients $(3,731$ with asthma and 2,138 with COPD), around half of the patients preferred the once-daily therapy, one-quarter were unsure, and one-quarter did not prefer the once-daily therapy. No significant correlation between once-daily preference and patients age or gender, disease severity, or frequency of exacerbations was detected when the whole population of patients was analyzed, while in COPD patients the once-daily preference was associated with a high self-perceived need to use controller medications. ${ }^{30}$ On the other hand, when short-acting beta-2 agonists (SABA) or short-acting muscarinic antagonists (SAMA) are taken based on pro re nata (PRN) use, patients' preference could be argued. A Cochrane systematic review including eleven studies on patients treated with SABA or SAMA concluded that the strategy to provide a SABA on a PRN basis and then continuing with regular use of either SABA or SAMA would seem cost-effective. ${ }^{31}$ However, one must consider that the GOLD guideline admits the PRN use of short-acting bronchodilators only in COPD exacerbations. ${ }^{18}$

Also, the device to inhale the drug is critical in influencing patient's appreciation for the prescribed therapy. Several recent studies addressed such aspect. Molimard et al assessed in real life the handling of inhaler device in around 3,000 COPD patients and its relationship with COPD exacerbations. ${ }^{32}$ Handling errors were observed in over $50 \%$ of inhalations, irrespective of the device used, and critical errors affecting drug delivery were made in $15.4 \%$ of cases with Breezhaler $^{\circledR}, 21.2 \%$ with Diskus ${ }^{\circledR}, 29.3 \%$ with Handihaler ${ }^{\circledR}$, $32.1 \%$ with Turbuhaler ${ }^{\circledR}, 43.8 \%$ with pressurized metereddose inhaler, and $46.9 \%$ with Respimat ${ }^{\circledR}$. Of interest, the need for hospitalization or emergency room visits for severe COPD exacerbation was $3.3 \%$ if no error in the use of device and $6.9 \%$ when critical errors were made $(P<0.05)$. These data suggest that training for correct use of inhaler devices should be a basic part of COPD management. ${ }^{32}$ In the randomized study by van der Palen et al, errors in the use of inhalers in patients with COPD or asthma who were naïve to the devices were investigated. The devices used were Ellipta ${ }^{\circledR}$, Diskus $^{\circledR}$, Turbuhaler $^{\circledR}$, Handihaler ${ }^{\circledR}$, and Breezhaler ${ }^{\circledR}$, and also metered-dose inhalers were included. A trained investigator assessed critical errors and demonstrated the correct use of the inhaler to patients who made errors. The results showed that fewer COPD patients made critical errors with Ellipta vs any other device. ${ }^{33}$

All the other studies were published in the current year. In the Real-life Experience and Accuracy of inhaLer use (REAL), the self-reported adherence of 764 COPD patients 
using various inhalers was evaluated by a questionnaire addressing real-world information on correct inhaler use, inhalation technique, device characteristics, training, ease of use, and adherence. The results indicated a significantly lower self-reported adherence in younger patients and patient's preference for in-person demonstration of the device use in respect to video demonstration ( $89 \%$ vs $58 \%$ ). In $29 \%$ of patients, the check for the correct use of the device was not performed, thus resulting in a significantly lower adherence than in patients who were checked $(P=0.020)$. Most patients using Breezhaler ${ }^{\circledR}$ reported to be confident of having taken a full dose compared with patients using Ellipta ${ }^{\circledR}$, Genuair $^{\circledR}$, or Respimat $^{\circledR}{ }^{34}$ A cohort of 130 COPD patients was evaluated by Man et al concerning patient's satisfaction and preference, and the error occurrence as well, with the use of the devices Genuair ${ }^{\circledR}$, Ellipta, ${ }^{\circledR}$ and Breezhaler ${ }^{\circledR}$. All patients learned to use the devices firstly by reading the instructions and then observing a demonstration. A significantly higher patient's satisfaction score of comfort was observed for Breezhaler $^{\circledR}$ compared with Ellipta $^{\circledR}(P<0.05)$, while the patient's satisfaction on self-assurance to have inhaled the entire dose was better for Genuair ${ }^{\circledR}$ compared with Ellipta $^{\circledR}$ $(P<0.0001)$ or Breezhaler ${ }^{\circledR}(P<0.05)$. After reading the instructions, more critical errors concerned Breezhaler ${ }^{\circledR}$, followed by Genuair ${ }^{\circledR}$ and Ellipta ${ }^{\circledR}$, while the demonstration decreased the number of such errors to one-third or lower. The authors concluded that Breezhaler ${ }^{\circledR}$ appeared to be more comfortable and easy to take, but patients made fewer critical errors when using Ellipta ${ }^{\circledR} \cdot{ }^{35}$ The ADVANTAGE study compared in naïve COPD patients the perception of dose delivery confirmation using the Breezhaler ${ }^{\mathbb{B}}$ and Ellipta ${ }^{\mathbb{R}}$ devices and patient's comfort with the inhalers' mouthpiece concerning the easiness in forming a tight seal around the mouthpiece. A new questionnaire on patient perception of inhaler (which was developed and tested in London through cognitive interviews of patients) was used. Patients included in the study filled in the questionnaire after a single inhalation of placebo by inhaler. The results showed that patients were significantly more confident $(P<0.0001)$ of the mechanism of Breezhaler ${ }^{\circledR}$ than that of the Ellipta ${ }^{\circledR}$ device and perceived better comfort $(P<0.0001)$ with the Breezhaler ${ }^{\circledR}$ than the Ellipta ${ }^{\circledR}$ mouthpiece. ${ }^{36}$ A randomized, Phase IV study evaluated the ability of 97 COPD patients to inhale with the least inspiratory effort using three devices (Breezhaler ${ }^{\circledR}$, Ellipta, ${ }^{\circledR}$ and HandiHaler ${ }^{\circledR}$ ), also assessing the effects on peak inspiratory flow (PIF). For each patient, the inhalation with the highest PIF value was selected for analysis. Both the highest mean PIF value and the lowest mean pressure drop values were detected with Breezhaler ${ }^{\circledR}$, followed by Ellipta $^{\circledR}$ and HandiHaler $^{\circledR}$. These results were comparable regardless of the patients' COPD severity, gender, or age. ${ }^{37}$

\section{Conclusion}

The effectiveness of the indacaterol/glycopyrronium combination in the treatment of severe COPD is supported by RCTs and meta-analysis. In several studies also PROs were evaluated, including patient's perception of breathlessness, physical functioning, global health status, QoL, use of rescue medications, and patient's report of COPD exacerbations. The PRO data were obtained from RCTs and also in real life, all studies demonstrating a clear improvement in patients' awareness of a better control of the disease. The latest literature added two important issues influencing patient's preference and adherence concerning inhaled drugs: the once-daily administration, which has an advantage over the twice-daily administration, and the device to be used. In most studies performed thus far, a patient's preference for Breezhaler ${ }^{\circledR}$, the device used for indacaterol/glycopyrronium combination, was reported, in terms of satisfaction, ease of use, less handling errors, and self-assurance to have inhaled the entire dose. Definitely, the information achieved through PROs, based on the relationship between PRO improvement and better disease control, is essential for the correct management of COPD patients.

\section{Disclosure}

The authors report no conflicts of interest in this work. Dr Cristoforo Incorvaia reports personal fees from Stallergenes Greer, outside the submitted work.

\section{References}

1. Bleecker ER, Siler T, Owen R, Kramer B. Bronchodilator efficacy and safety of indacaterol $150 \mu \mathrm{g}$ once daily in patients with COPD: an analysis of pooled data. Int J Chron Obstruct Pulmon Dis. 2011;6:431-438.

2. Kerwin EM, Williams J. Indacaterol $75 \mu \mathrm{g}$ once daily for the treatment of patients with chronic obstructive pulmonary disease: a North American perspective. Ther Adv Respir Dis. 2013;7(1):25-37.

3. Ridolo E, Montagni M, Olivieri E, Riario-Sforza GG, Incorvaia C. Role of indacaterol and the newer very long-acting $\beta 2$-agonists in patients with stable COPD: a review. Int J Chron Obstruct Pulmon Dis. 2013; $8: 425-432$.

4. Metaxas EI, Balis E. The safety of indacaterol for the treatment of COPD. Expert Opin Drug Saf. 2018;17(6):637-642.

5. Buhl R, Banerji D. Profile of glycopyrronium for once-daily treatment of moderate-to-severe COPD. Int J Chron Obstruct Pulmon Dis. 2012;7:729-741.

6. Carter NJ. Inhaled glycopyrronium bromide: a review of its use in patients with moderate to severe chronic obstructive pulmonary disease. Drugs. 2013;73(7):741-753.

7. Molimard M, D'Andrea P. Once-daily glycopyrronium via the Breezhaler ${ }^{\circledR}$ device for the treatment of COPD: pharmacological and clinical profile. Expert Rev Clin Pharmacol. 2013;6(5):503-517. 
8. Riario-Sforza GG, Ridolo E, Riario-Sforza E, Incorvaia C. Glycopyrronium bromide for the treatment of chronic obstructive pulmonary disease. Expert Rev Respir Med. 2015;9(1):23-33.

9. Schachter EN. Indacaterol/glycopyrronium bromide fixed-dose combination for the treatment of COPD. Drugs Today. 2013;49(7):437-446.

10. Matera MG, Rogliani P, Cazzola M. QVA149 (indacaterol/ glycopyrronium) for the treatment of chronic obstructive pulmonary disease. Expert Opinion on Pharmacotherapy. 2015;16(7):1079-1090.

11. Ridolo E, Montagni M, Riario-Sforza GG, Baroni M, Incorvaia C. Combination therapy with indacaterol and glycopyrronium bromide in the management of COPD: an update on the evidence for efficacy and safety. Ther Adv Respir Dis. 2015;9(2):49-55.

12. Ficker JH, Rabe KF, Welte T. Role of dual bronchodilators in COPD: A review of the current evidence for indacaterol/glycopyrronium. Pulm Pharmacol Ther. 2017;45:19-33.

13. Han J, Dai L, Zhong N. Indacaterol on dyspnea in chronic obstructive pulmonary disease: a systematic review and meta-analysis of randomized placebo-controlled trials. BMC Pulm Med. 2013;25(13):26.

14. Chung VCH, Ma PHX, Hui DSC, Tam WWS, Tang JL. Indacaterol for chronic obstructive pulmonary disease: systematic review and metaanalysis. PLoS One. 2013;8(8):e70784.

15. Geake JB, Dabscheck EJ, Wood-Baker R, Indacaterol CCJ. A once-daily beta2-agonist, versus twice-daily beta-agonists or placebo for chronic obstructive pulmonary disease. Cochrane Database Syst Rev. 2015;1: CD010139.

16. Ismaila AS, Huisman EL, Punekar YS, Karabis A. Comparative efficacy of long-acting muscarinic antagonist monotherapies in COPD: a systematic review and network meta-analysis. Int J Chron Obstruct Pulmon Dis. 2015;10:2495-2517.

17. Rosselli D, Karpf E, Olaya A, et al. Systematic review and metaanalysis of the effectiveness and safety of combination therapy with Glycopirronium-Indacaterol compared with other first line therapies in patients with chronic obstructive pulmonary disease. Value Health. 2015;18(7):A494.

18. Global Strategy for the Diagnosis, Management and Prevention of Chronic Obstructive Pulmonary Disease. 2018. Available from: http:// goldcopd.org/glogal-strategy-management-prevention.copd-2018. Accessed October 13, 2018.

19. Price DB, Østrem A, Thomas M, Welte T. Dual bronchodilation in COPD: lung function and patient-reported outcomes - a review. Int $J$ Chron Obstruct Pulmon Dis. 2016;12:141-168.

20. Donohue JF, Jones PW, Bartels C, et al. Correlations between FEV and patient-reported outcomes: A pooled analysis of 23 clinical trials in patients with chronic obstructive pulmonary disease. Pulm Pharmacol Ther. 2018;49:11-19.

21. Wedzicha JA, Decramer M, Ficker JH, et al. Analysis of chronic obstructive pulmonary disease exacerbations with the dual bronchodilator QVA149 compared with glycopyrronium and tiotropium (SPARK): a randomised, double-blind, parallel-group study. Lancet Respir Med. 2013;1(3):199-209.

22. Dahl R, Jadayel D, Alagappan VK, Chen H, Banerji D. Efficacy and safety of QVA149 compared to the concurrent administration of its monocomponents indacaterol and glycopyrronium: the BEACON study. Int J Chron Obstruct Pulmon Dis. 2013;8:501-508.

23. Mahler DA, Decramer M, D'Urzo A, et al. Dual bronchodilation with QVA149 reduces patient-reported dyspnoea in COPD: the BLAZE study. Eur Respir J. 2014;43(6):1599-1609.

Patient Preference and Adherence

\section{Publish your work in this journal}

Patient Preference and Adherence is an international, peer-reviewed, open access journal that focuses on the growing importance of patient preference and adherence throughout the therapeutic continuum. Patient satisfaction, acceptability, quality of life, compliance, persistence and their role in developing new therapeutic modalities and compounds to optimize
24. Wedzicha JA, Banerji D, Chapman KR, et al. IndacaterolGlycopyrronium versus Salmeterol-Fluticasone for COPD. $N$ Engl J Med. 2016;374(23):2222-2234.

25. Kardos $\mathrm{P}$, Hagedorn-Peinz I. The impact of indacaterol/glycopyrronium fixed-dose combination versus tiotropium monotherapy on lung function and treatment preference: a randomized crossover study - the FAVOR study. Int J Chron Obstruct Pulmon Dis. 2018;13:69-77.

26. Tsiligianni I, Mezzi K, Fucile S, et al. Response to Indacaterol/ Glycopyrronium (IND/GLY) by sex in patients with COPD: a pooled analysis from the IGNITE program. COPD. 2017;14(4):375-381.

27. Anzueto AR, Kostikas K, Mezzi K, et al. Indacaterol/glycopyrronium versus salmeterol/fluticasone in the prevention of clinically important deterioration in COPD: results from the FLAME study. Respir Res. 2018;19(1):121.

28. Płusa T; Physicians From Medical Centers In Poland GO. Evaluation of effect of indacaterol (Onbrez) and/or glycopyrronium (Seebri) treatment on Quality of Life of COPD patients in medical practice in Poland - observational study (OSQO). Pol Merkur Lekarski. 2017; 43(256):158-162.

29. Kocks JWH, Seys SF, van Duin TS, Diamant Z, Tsiligianni IG. Assessing patient-reported outcomes in asthma and COPD patients: which can be recommended in clinical practice? Curr Opin Pulm Med. 2018;24(1):18-23.

30. Price D, Lee AJ, Sims EJ, et al. Characteristics of patients preferring once-daily controller therapy for asthma and COPD: a retrospective cohort study. Primary Care Respiratory Journal. 2013;22(2):161-168.

31. Appleton S, Jones T, Poole P. Ipratropium bromide versus short acting beta-2 agonists for stable chronic obstructive pulmonary disease. Cochrane Database Syst Rev. 2006;2:CD001387.

32. Molimard M, Raherison C, Lignot S, et al. Chronic obstructive pulmonary disease exacerbation and inhaler device handling: real-life assessment of 2935 patients. Eur Respir J. 2017;49(2):1601794.

33. van der Palen J, Thomas M, Chrystyn H, et al. A randomised openlabel cross-over study of inhaler errors, preference and time to achieve correct inhaler use in patients with COPD or asthma: comparison of ELLIPTA with other inhaler devices. NPJ Prim Care Respir Med. 2016; 26(1):16079.

34. Price D, Keininger DL, Viswanad B, Gasser M, Walda S, Gutzwiller FS. Factors associated with appropriate inhaler use in patients with COPD lessons from the REAL survey. Int $J$ Chron Obstruct Pulmon Dis. 2018;13:695-702.

35. Man KN, Tian Z, Lam DC, Wan JMF, Tan-Un KC. Satisfaction, preference and error occurrence of three dry powder inhalers as assessed by a cohort naïve to inhaler operation. Int J Chron Obstruct Pulmon Dis. 2018; 13:1949-1963.

36. Altman P, Bergna MA, Garcia GR, Guerin T, Pino AV, Whiteford JL. Patient perception of Breezhaler ${ }^{\circledR}$ and Ellipta ${ }^{\circledR}$ device feedback mechanisms in COPD: The ADVANTAGE Study. Curr Med Res Opin. 2018;50:1-7.

37. Altman P, Wehbe L, Dederichs J, et al. Comparison of peak inspiratory flow rate via the Breezhaler ${ }^{\circledR}$, Ellipta ${ }^{\circledR}$ and HandiHaler ${ }^{\circledR}$ dry powder inhalers in patients with moderate to very severe COPD: a randomized cross-over trial. BMC Pulm Med. 2018;18(1):100.

clinical outcomes for existing disease states are major areas of interest for the journal. This journal has been accepted for indexing on PubMed Central. The manuscript management system is completely online and includes a very quick and fair peer-review system, which is all easy to use. Visit http://www. dovepress.com/testimonials.php to read real quotes from published authors. 